\title{
Quadrilhas juninas como um movimento de juventude em Rio Branco, Acre
}

\author{
Eduardo Di Deus \\ Doutorando em Antropologia Social (Universidade de Brasília), Brasília' \\ Distrito Federal, Brasil \\ eduardodideus@gmail.com
}

\begin{abstract}
Resumo As quadrilhas juninas contemporâneas na cidade de Rio Branco, Acre, mobilizam um grande número de pessoas em suas atividades, que não se restringem ao calendário de festejos juninos. Elas constituem um dos mais fortes movimentos culturais desse estado. Sua força se dá tanto no contexto de interlocução com as políticas públicas para a cultura quanto em suas comunidades de origem, onde os grupos ocupam espaços públicos e constituem um ambiente de socialidades da juventude. Este artigo propõe-se a apresentar reflexões de pesquisa antropológica sobre a construção social da pessoa do brincante de quadrilhas juninas nos bairros de Rio Branco, em suas articulações com os processos de aprendizado das técnicas do corpo.
\end{abstract}

Palavras-chave: quadrilhas juninas, juventude, construção da pessoa, técnicas do corpo, aprendizagem.

$\mathrm{R}$ io Branco, capital do estado do Acre. Atualmente com quase 350 mil habitantes, metade da população estadual, está localizada no oeste da Amazônia brasileira. Na década de 1970, contava com menos de 50 mil habitantes urbanos. Essa cidade vivenciou um expressivo crescimento demográfico a partir das décadas de 1970 e 1980, quando grande parte dos bairros se formou e/ou cresceu a partir do êxodo rural estimulado pelas políticas desenvolvimentistas da época, baseadas na transformação dos antigos seringais em fazendas de gado (Morais, 2001).

Klein (2009) retratou a formação de alguns bairros populares riobranquenses, entre eles, os do Triângulo Novo e João Eduardo, localizados respectivamente em duas regiões da cidade, o $2^{\circ}$ Distrito e a baixada da Sobral. Ao recontar a história de movimentos comunitários e de direitos humanos, o autor resgatou parte da luta por moradia e cidadania dessas pessoas que vinham do interior, pelo estabelecimento de forma digna no ambiente urbano. Cardia (2010) etnografou a memória de migrantes seringueiros e de colonos que se instalaram em um bairro do $2^{\circ}$ distrito de Rio Branco, o bairro Cidade Nova, retratando as memórias desses migrantes na construção de novas vidas.

Os bairros populares na Rio Branco de hoje são espaços dinâmicos de transformação e interação social. Espaços privilegiados em que algumas manifestações culturais mobilizam grande número de jovens, filhos e netos da geração que há alguns anos realizou as migrações acima referidas. Capoeira, hip hop e danças de rua, bandas marciais ou fanfarras e quadrilhas juninas são alguns dos principais movimentos que

1. Quando da realização da pesquisa que originou o presente artigo, o autor se encontrava como Professor Temporário do Centro de Filosofia e Ciências Humanas (CFCH) da Universidade Federal do Acre - UFAC. 
se destacam pelo grande número de participantes. O termo movimento é utilizado pelos próprios participantes dessas atividades, e possui uma conotação política, da organização como agentes (formalizados ou não) na esfera pública do município e do estado. Assim, é comum falar-se de movimento junino, movimento da capoeira, ou movimento hip hop, por exemplo. Curiosa e coincidentemente, são também atividades eminentemente cinestésicas, nas quais os movimentos corporais são fundamentais.

Os bairros e regiões anteriormente mencionados, e outros que surgiram ou cresceram nos mesmos processos sócio-históricos, são os espaços privilegiados das socialidades ${ }^{2}$ juvenis envolvidas nesses movimentos. Este trabalho lança um olhar para um deles, o movimento junino, com atenção para suas práticas, processos de aprendizagem e relações.

\section{Movimentos em Rio Branco, Acre: as quadrilhas juninas}

As quadrilhas juninas contemporâneas em Rio Branco mobilizam um grande número de pessoas em suas ações, que não se restringem ao calendário de festejos juninos. Os ensaios desses grupos têm início nos primeiros meses do ano, como preparação para apresentações e concursos que ocorrem entre maio e julho. Para além disso, ao longo do ano ocorrem outras atividades internas a cada quadrilha ou integrando os diversos grupos, como seminários, torneios esportivos, blocos de carnaval e festas.

Os brincantes ${ }^{3}$ com alguma diferenciação no grau de dedicação, participam intensamente de suas quadrilhas. Em sua maioria são jovens trabalhadores e estudantes, que investem grande parte de seu tempo livre em ensaios (que se tornam diários nos meses anteriores aos festejos), em encontros de preparação de cenários e figurinos, e até mesmo na organização do movimento junino. Desde 2001 existe a Liga de Quadrilhas Juninas do Acre (Liquajac), filiada à Confederação Brasileira de Entidades de Quadrilhas Juninas (Confebraq). Aproximadamente 16 quadrilhas juninas integram a Liquajac, mas o número de grupos ativos varia a cada ano, com o surgimento e encerramento de grupos.

A Liga e os quadrilheiros são protagonistas, por exemplo, nas instâncias de participação do Conselho Municipal de Políticas Culturais de Rio Branco, cujo formato inovador estimula a participação direta dos "fazedores de cultura". ${ }^{4}$ A interlocução com políticas públicas estaduais e municipais e a interação com o movimento junino nacional são focos de atenção de uma parcela dos brincantes, sobretudo os coordenadores dos grupos. De fato, as quadrilhas juninas constituem um dos mais fortes movimentos culturais do estado. Sua força ocorre tanto no contexto de interlocução com as políticas públicas para a cultura quanto em suas comunidades de origem, onde os grupos ocupam espaços públicos e constituem ambientes de socialidade de pessoas jovens.

Com forte presença em bairros populares da capital acreana, as quadrilhas de Rio Branco são marcadas por um aspecto discutido por Chianca (2007): a imagem do homem do campo expressa no contexto urbano. Segundo a autora, as quadrilhas de Natal, capital do Rio Grande do Norte, mobilizam as imagens do interior e do matuto/ caipira, por meio da memória dos migrantes vindos das zonas rurais. As festas juninas são o momento em que a "construção citadina do rural" e a "memória subjetiva dos trabalhadores migrantes" (Chianca, 2007, p. 48) se misturam em uma celebração das raízes interioranas.

No Acre, segundo Costa (2011, p. 33) - um quadrilheiro que realizou pesquisa de conclusão de curso sobre a história das quadrilhas juninas -, o matuto é relacionado à figura do seringueiro, o trabalhador dos seringais, oriundo majoritariamente do nordeste brasileiro, que à floresta amazônica migrou em busca de novas condições de vida, deixando para trás o árido sertão. Desta forma, o matutoacreano, se assim podemos considerar, é também esse matuto nordestino que se aventura no interior da floresta - o seringueiro - e que em um momento histórico posterior migra para a cidade, passando a habitar os bairros populares, locais onde hoje as quadrilhas juninas e outros movimentos têm grande força. A memória dessa dupla migração está viva nas quadrilhas da cidade e é revivida constantemente em seus enredos. ${ }^{5}$

\footnotetext{
2. O termo "socialidade" é utilizado no sentido atribuído por M. Strathern (2006), como referindo-se à "criação e manutenção de relações" (p. 40). A ênfase, aqui, recai nas relações estabelecidas contextualmente, e não em processos tradicionais que se impõem aos sujeitos por totalidades uniformatadas (culturas, sociedades).

3. Brincante é aquele que participa das quadrilhas juninas, termo que se confunde em alguns momentos com o de quadrilheiro. Parece-me que o primeiro termo remete aos participantes mais diretamente ativos nas atividades de dança e encenação, ao passo em que o segundo emerge como uma categoria aplicada a pessoas que não mais participam ativamente dos grupos, mas que continuam como parceiros e apoiadores.

4. Sobre o formato específico desse Conselho Municipal, ver: Lucena e Barros (2011).

5. Para uma interpretação a respeito do processo histórico de ocupação do estado do Acre, com ênfase na sociedade do seringal, consultar Ranzi (2008). Em Almeida (1993), há um minucioso estudo sobre o modo de vida, história, economia doméstica e trabalho nas "colocações", as unidades sociais nas quais os seringueiros se organizam nos seringais, com foco territorial no vale do alto rio Juruá, também no estado do Acre.
} 
Por outro lado, ouvimos relatos de membros de algumas quadrilhas dando conta de que, em alguns momentos, a recorrência da tematização da vida no seringal e/ou das origens nordestinas como enredos nos grupos quadrilheiros é reforçada pelos jurados, porque quando os temas se afastam desses motes, "os jurados canetam". Ou seja, dão notas mais baixas a enredos menos vinculadas à história e a uma determinada visão de "tradição". Aprofundaremos esse ponto mais adiante.

Considerando esta configuração histórica, os grupos quadrilheiros mostram contextos potencialmente reveladores dos processos de construção da pessoa nas classes trabalhadoras urbanas da capital acreana. Valemo-nos das contribuições de Duarte (1986), que, em seus estudos sobre os nervos e o nervoso com grupos de trabalhadores no estado do Rio de Janeiro, considerou a constituição da pessoa nas classes trabalhadoras urbanas como processo diferenciado da "concepção particular de pessoa" da sociedade moderna. No presente trabalho pretendemos apresentar algumas reflexões baseadas em pesquisa realizada com quadrilhas juninas da cidade de Rio Branco no ciclo junino de 2012. Buscamos pensar os processos de construção da pessoa do brincante de quadrilhas juninas em Rio Branco em suas relações com o aprendizado de técnicas corporais, na medida em que se trata de uma atividade eminentemente técnica e corporal. Antes, porém, é importante situar esta proposta no quadro dos estudos sobre quadrilhas juninas no Brasil.

\section{Estudos sobre quadrilhas juninas no Brasil}

A quadrilha é uma dança de origem europeia, trazida ao Brasil no início do século 19 pela corte portuguesa em formato palaciano, inicialmente praticada pela elite nobre, no período imperial. Aos poucos popularizou-se, passando a ser praticada também em regiões interioranas. Com a mudança para o regime republicano, essa dança, associada ao regime monárquico, teria sido abolida das festas dos citadinos ricos, mas mantida principalmente nas zonas rurais, passando ao longo do tempo a ser considerada uma das manifestações representativas do interior, da roça, do sertão, quando de seu retorno ao contexto urbano, em momento posterior, associada a festejos do catolicismo popular. A quadrilha é, portanto, uma dança de origem nobre e palaciana que se tornou uma das manifestações das culturas populares brasileiras (Chianca, 2007, p. 50-51).
A partir desta história de transformações, os estudos desenvolvidos sobre quadrilhas juninas, em específico, e sobre culturas populares, em geral, tendem a abordar esses fenômenos por meio da chave conceitual de uma controversa relação entre os processos de reprodução da tradição, por um lado, e de inovação e mudança, por outro. Em uma rica etnografia, Menezes Neto (2008) analisa os "usos da categoria tradição" nas quadrilhas juninas de Recife, descrevendo o que nomeia de "campo de embates simbólicos", no interior do qual as quadrilhas matutas foram dando lugar às chamadas estilizadas e, posteriormente, às recriadas. A coreografia, a musicalidade, o figurino, a encenação do casamento na roça, entre outros elementos das quadrilhas, são analisados a partir das transformações verificadas ao longo dos anos, mediadas pelo que o autor chama de "censura preventiva" no "controle dos conteúdos da tradição", 6 exercida por uma diversidade de agentes: os próprios quadrilheiros, suas comunidades, os concursos e competições, os jurados e o poder público. As mudanças, segundo Menezes Neto, são parte da própria tradição, e reguladas pelo conjunto de agentes envolvidos nesse campo.

Questões semelhantes foram elaboradas em outros contextos etnográficos. Chianca (2007, p. 51-56) discute o surgimento das quadrilhas estilizadas em Natal (RN) na década de 1990, vinculado aos concursos e festivais de quadrilhas, como contexto de transformações na tradição matuta, dentro de sua já mencionada análise da identidade do homem do campo no contexto urbano. L. Silva (mimeo), considerando o "maior São João do Mundo", em Campina Grande (PB), lança um olhar crítico, mediado por teorias da comunicação, para as transformações nas "identidades culturais no nordeste brasileiro" a partir da atuação da mídia nos festejos juninos, no processo de "espetacularização" de manifestações de cultura popular. P. Silva (2009), ao etnografar os "bastidores" de uma quadrilha junina sergipana, identifica processos de transformação nos passos, marcações e figurinos, em uma "profissionalização" influenciada pelos concursos.

Costa (2011) e Klein (mimeo) apresentam olhares históricos das transformações verificadas ao longo dos anos nas quadrilhas rio-branquenses, transformações estas também vinculadas ao surgimento dos festivais competitivos, principalmente os concursos de quadrilhas do SESC e da Fundação de Cultura do Estado, o chamado "Estadual". Alvim, Lobo e Encarnação (2009) discutem, a partir do olhar da etnocenologia, que as quadrilhas juninas acabam por influenciar outras manifestações cênicas na região. Ao analisar peças teatrais de grupos do interior do estado do Acre, verificaram a incorporação, em suas

6. Conceitos que o autor toma emprestado respectivamente de Peter Burke e Lady Selma Albernaz, para tratar do processo de regulação do que muda e o que permanece como "tradição" em determinadas práticas de culturas populares. 
apresentações, de elementos da dramaturgia popular presentes na encenação dos casamentos na roça, especificamente o personagem cômico do noivo. Isso mostra que, se por um lado, as quadrilhas juninas são influenciadas por padrões das artes cênicas, gerando o chamado processo de profissionalização, por outro, em determinados contextos podem exercer influências na dramaturgia para além dos festejos juninos.

Com enfoques teóricos e objetivos diferentes, grande parte dos estudos sobre quadrilhas juninas tem como um dos problemas centrais a questão da manutenção/transformação das tradições quadrilheiras, consideradas a partir, principalmente, do enfoque nas disputas simbólicas e nas transformações estéticas verificadas em cada contexto etnográfico, mapeando agentes e forças transformadoras, por um lado, e conservadoras, por outro.

\section{Pessoa e técnicas do corpo}

$\mathrm{Na}$ pesquisa que baseia este trabalho, tomamos como ponto de partida os processos práticos de aprendizagem das técnicas corporais envolvidas nas quadrilhas, concordando com o argumento de C. Sautchuk (2007, p. 13-15), segundo o qual a aprendizagem de determinadas técnicas pode ser reveladora dos processos de construção da pessoa, no sentido de que os "engajamentos corporais em dado contexto técnico" se relacionam à "configuração do humano" nesse contexto. Propomos uma abordagem para estudar as quadrilhas juninas buscando ensinamentos e contribuições na antropologia das técnicas e também na tradição de estudos em antropologia sobre as classes trabalhadoras urbanas, com uma especial consideração ao processo de construção da pessoa.

Uma referência fundamental neste sentido é o trabalho de Marcel Mauss a respeito das técnicas do corpo, entendidas como "maneiras pelas quais os homens, de sociedade a sociedade, de uma forma tradicional, sabem servir-se de seu corpo" (2003, p. 401). Discutimos, em outro momento (Di Deus, 2007, p. 20-31), como, somados a esse estudo já mencionado, as análises de Mauss sobre as relações entre antropologia e psicologia e sobre a ideia de morte configuram uma guinada em direção a uma nova conceituação do social e do humano, sintetizada no conceito de homem total, representado pelas dimensões fisiológica, psicológica e sociológica. Assim o autor argumenta, no estudo sobre as técnicas do corpo:

Não se podia ter uma visão clara de todos esses fatos, da corrida, do nado, etc, senão fazendo intervir uma tríplice consideração em vez de uma única, fosse ela mecânica e física, como uma teoria anatômica e fisiológica da marcha, ou, ao contrário, psicológica ou sociológica. É o tríplice ponto de vista, o do "homem total”, que é necessário. (Mauss, 2003, p. 404-405)

Em outro artigo seminal a respeito da noção de pessoa, Mauss (2003, p. 367-397) apresenta base etnográfica e histórica para argumentar a favor da existência de uma variabilidade dessa noção em diferentes grupos sociais e épocas, e para relativizar a noção ocidental de pessoa. $\mathrm{O}$ autor abre caminho, dessa forma, para a consideração conjunta dos processos particulares de construção da pessoa e de aprendizagem de técnicas do corpo. Neste sentido, a abordagem de Tim Ingold (2000) sobre técnicas, que faz por meio da noção de skill, também pode contribuir para nossos objetivos. A aprendizagem de técnicas pode ser entendida como um processo de crescimento, no qual habilidades emergem nos contextos relacionais de desenvolvimento de "pessoas-organismos".

Um estudo inspirador para esse tipo de abordagem é o de Wacquant (2002), que se integrou ao cotidiano de um ginásio de boxe para compreender a vida em um gueto de uma grande cidade americana, acompanhando e vivenciado o processo de treinamento e aprendizado dessa atividade. $\mathrm{O}$ autor percebeu a articulação entre o aprendizado do boxear e o modo de ser daquele grupo que estudava. Ao mencionar o processo de transmissão das técnicas e da socialidade do boxe, defende ser esta uma "prática essencialmente corporal e pouco codificada, cuja lógica só pode ser apreendida em ação, corresponde um modo de inculcar implícito, prático e coletivo. A transmissão do pugilismo efetua-se de uma forma gestual, visual e mimética”(Wacquant, 2002, p. 120).

Assim, se os estudos sobre quadrilhas citados focalizam a dialética entre transformação e manutenção das tradições juninas, nosso olhar volta-se para os modos pelos quais as técnicas corporais se reproduzem em processos práticos de aprendizagem presentes nos grupos quadrilheiros, ao mesmo tempo que se processa a construção da pessoa nesses contextos. Ao transpor essa perspectiva para o estudo das técnicas corporais envolvidas na construção do brincante de quadrilhas, estamos atentos a uma diferença fundamental: enquanto nos exemplos anteriormente citados tratava-se de contextos de trabalho, urbano-industrial, nas quadrilhas as técnicas e socialidades envolvidas dizem respeito ao âmbito das atividades a que grupos de trabalhadores urbanos (do comércio e da indústria, empregadas domésticas, camelôs e estudantes) se dedicam em suas horas de tempo livre. ${ }^{7}$ Mesmo assim, percebe-se que a reprodução das quadrilhas juninas está relacionada ao que Jadir

7. Ingold (2000, p. 323-338) discute a naturalização que as sociedades urbano-industriais realizam dessa oposição entre trabalho e tempo livre, e que não seria evidente em sociedades "tradicionais", por exemplo, nas quais a própria experiência do tempo é diferente. É nas sociedades 
Pessoa (2005), recorrendo a um conceito proposto por Carlos Rodrigues Brandão, nomeia de "situações de aprendizagem", para tratar de como se dá a transmissão dos conhecimentos e técnicas em cultura popular.

As danças, cânticos, ornamentos e objetos simbólicos são também socialização das novas gerações. Comportam também, ao mesmo tempo em que são construídos e comunicados, uma docência, uma transmissão de valores, um ensinamento sobre esses mesmos sentidos. Uma criança que está imitando a batida do bastão do palhaço enquanto canta uma folia de reis ou que está aprendendo o compasso da batida de um tambor na congada ou no bumba-meu-boi, não está aprendendo apenas um ritual. Está aprendendo com os que já o praticam e reproduzem, o modo como eles organizam seu mundo e sua existência: sua crença, sua sociabilidade, sua disposição para a interação com outras pessoas. (Pessoa, 2005, p. 12)

No campo de estudos sobre manifestações da chamada "cultura popular", encontramos um rico estudo etnográfico sobre os repentistas do nordeste brasileiro, também chamados de cantadores, com o foco em suas práticas. É o estudo de J. Sautchuk (2012), que oferece uma interessante alternativa para o dilema entre tradição e modernidade. O autor defende não haver necessidade de abordar os fenômenos por meio dessa oposição, na medida em que os próprios cantadores manifestam uma visão de seu ofício não como "tradicional", mas como algo moderno (J. Sautchuk, 2012, p. 42). Os quadrilheiros de Rio Branco, mesmo se vendo como representantes de uma "cultura popular", parecem próximos desse ponto de vista. O olhar de J. Sautchuk volta-se para as práticas, para como as"habilidades" da cantoria, como o tocar a viola, a métrica, a rima e o improviso são aprendidos e mobilizados na vida dos cantadores a partir do engajamento dos neófitos, desde jovens, em um contexto propício a esse aprendizado, principalmente em algumas regiões do interior do nordeste brasileiro. $\mathrm{O}$ autor, que se submeteu ao aprendizado de se tornar cantador, assim discorre sobre esse tema:

Um processo de aprendizado é também um processo de construção de sujeitos, pois, para além do desenvolvimento de conhecimentos e capacidades específicas, implica a participação crescente em comunidades de praticantes (...). O que ocorre num processo de aprendizado como o de um cantador, ao longo dos anos, é que o fazer vai aos poucos fazendo o sujeito. (J. Sautchuk, 2012, p. 129)

E prossegue, atribuindo grande valor às interações e relações na consideração das habilidades:

As habilidades dos repentistas são vinculadas às atividades que as evocam. Quer dizer, destrezas como a métrica e a capacidade de discorrer em versos sobre assuntos diversos constituem propriedades cognitivas e estas não são fenômenos estáticos que indivíduos isolados possuem ou não possuem em suas mentes, mas habilidades construídas e acionadas em contextos práticos de interação, isto é, não existe uma habilidade orgânica adquirida como tal, mas destrezas que emergem das interações. (J. Sautchuk, 2012, p. 155)

Isso nos ajuda a pensar o tornar-se quadrilheiro junto com o aprendizado da técnica, o aprender a dançar quadrilha e a encenar o casamento caipira a partir do engajamento prático dos brincantes na vida compartilhada dos grupos quadrilheiros, em uma teia de relações em que são protagonistas, verdadeiros pesquisadores e agentes ativos de um processo de inserção na vida comum dos bairros populares de Rio Branco. A mudança é parte daquilo que as pessoas realizam em conjunto, e isso não é diferente nas práticas de quadrilheiros e quadrilheiras de Rio Branco. Em vez de considerar sua ação como parte de totalidades uniformatadas, estanques, pensaremos sobre como, nas relações, ocorre o aprendizado de técnicas, a inserção em socialidades comunitárias e a construção da pessoa do quadrilheiro.

\section{Aprendizagem nas quadrilhas de Rio Branco}

Apesquisa foi realizada com o movimento quadrilheiro de Rio Branco em momentos importantes do calendário junino de 2012. Mantivemos conversas iniciais com agentes importantes nesse campo, como gestores públicos, dirigentes da Liquajac e coordenadores dos grupos. Paralelamente fizemos observações em eventos que envolviam várias quadrilhas, os chamados esquentas juninos, realizados em espaços públicos dos bairros. Em um determinado momento, no início do mês de maio, optamos por acompanhar de perto os ensaios e demais eventos de uma qua-

industriais que surge a ideia de que "tempo é dinheiro". Parece-nos que as ideias de "lazer" ou "hobby", como atividades opostas ao "trabalho e, que ocupam o "tempo livre", não se ajustam totalmente à maneira pela qual os brincantes se engajam nas quadrilhas juninas, não obstante haja uma concepção de que sejam essas atividades paralelas a profissões ou estudos. A proeminência que essas atividades ganham na vida dos brincantes indicam que trabalho, estudo e atividades quadrilheiras aparecem articuladas, e não cindidas, na corrente da vida (social) dos brincantes/trabalhadores/estudantes. 
drilha em específico: a Matutos na Roça, ${ }^{8}$ localizada no bairro do Aeroporto Velho, na região conhecida como baixada da Sobral, ou baixada do sol. Essa região da cidade concentra grande população das classes trabalhadoras do município e abriga também quatro outros grupos quadrilheiros. Nos meses anteriores aos festivais, os ensaios do grupo são realizados todos os dias da semana, em horário avançado da noite, a partir das $22 \mathrm{~h}$, quando as pessoas já encerraram seus compromissos de trabalho ou estudo. É uma rotina intensa, à qual essas pessoas dedicam grande parte de seu tempo livre, engajando-se nas atividades do grupo.

Parte da minha interação com a Matutos ocorreu à semelhança da participação observante, tal como descreveu Wacquant (2002) em sua pesquisa, mencionada anteriormente.De modo análogo ao que foi vivido por esse autor, nos primeiros ensaios que acompanhei da Matutos fui sistematicamente convidado a tomar parte na dança, na medida em que minha frequência assídua aos ensaios era interpretada como sinal desse interesse.

Foi possível identificar a existência de um processo de transmissão intergeracional das técnicas e conhecimentos, visto que alguns brincantes foram iniciados nas quadrilhas ao conviverem nesses ensaios desde pequenos. Grande parte dos brincantes relata que começou a ensaiar e a participar de apresentações em idades que variam entre 12 e 14 anos, enquanto outros afirmaram ter começado mais tardiamente, entre os 15 e 20 anos. A dança atualmente praticada no Acre, com um ritmo muito acelerado, atua como limitador para que a faixa etária dos brincantes ativos não ultrapasse, em média, os 30 anos. $\mathrm{O}$ coordenador de um outro grupo, que também é marcador, certa vez revelou-me que se considerava "velho" para a dança, com uma idade entre 25 e 30 anos. Conheci alguns brincantes ativos (isto é, que tomam parte na dança e/ou na encenação do casamento caipira) com idade entre 30 e 40 anos, mas a maioria dos quadrilheiros dessa faixa etária realiza outras atividades no movimento, tais como: coordenação, marcação, elaboração de enredos, confecção de adereços e figurinos, articulação política, entre outras.

\section{Crianças brincantes}

Chama a atenção a presença de crianças nos ensaios, em geral filhos dos brincantes e coordenadores, que passam o tempo se divertindo, jogando bola e eventualmente imitando os passos e ações dos adultos. Nas apresentações em concursos, essas crianças recebem figurinos idênticos aos dos adultos, e participam das apresentações como mascotes, dançando livremente ao redor da quadrilha que se apresenta. Em geral entre 12 e 15 anos, a depender do grau de maturidade de cada um, eles passam a participar oficialmente das apresentações, na maioria das vezes com grande domínio da dança e dos códigos do grupo.

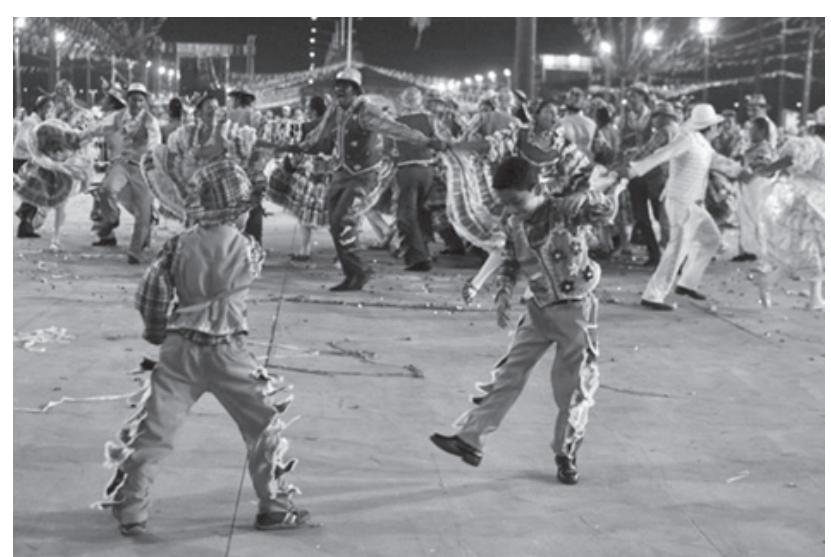

Figura 1 - Dois matutinos inseridos na apresentação no Concurso Estadual de Quadrilhas, julho/2012 Fonte: Foto de Renato Reis.

Alguns garotos, com idades entre 7 e 8 anos, estavam sempre presentes nos ensaios da Matutos na Roça acompanhando seus pais, coordenadores e brincantes mais experientes. Frequentemente jogavam futebol à margem da quadra onde ocorria o ensaio, em alguns momentos até sendo repreendidos por invadirem o espaço. Fui surpreendido pela desenvoltura que esses garotos demonstraram no dia das apresentações, e pela destreza que exibiam ao reproduzir os passos de dança. Destreza talvez maior do que a de alguns "novatos" adolescentes/jovens que buscavam se integrar ao grupo sem experiências prévias de dança. Um dos coordenadores da Matutos assim falou sobre a inserção de seu filho:

Os filhos a gente vai, no meu caso, eu vou pra quadra de ensaio eu levo a minha mulher, o meu filho, que já vai vendo, vai tendo aquela convivência, vai jogando uma bola... Quando dá fé, está dançando quadrilha. Ele vai vendo, vai gostando, e da convivência vai se integrando ao grupo. Meu filho José está com 8, a Michele está com 14. Este ano [2013] vai ser o primeiro ano dela. Já vamos botar ela pra ensaiar pra ver se tem ritmo. Se não tiver ritmo toma peia, pra no outro ano entrar... A peia que eu falo não é peia, não [agressão física], é ensaiar, suar bastante! Tanto meus filhos quanto os filhos do Cleyber [marcador da Matutos até 2012], quanto outros filhos de quadrilheiros entraram [na

8. A Matutos na Roça foi formada no início dos anos 2000, a partir de uma antiga quadrilha, chamada Tchaca-Tchaca na Mutchaca. A mudança de nome é atribuída a um conflito com o antigo coordenador, que proibiu o uso do nome original. Também é um marco de um novo momento do grupo, no qual os brincantes relatam ter sido conquistadas muitas vitórias em festivais e concursos. 
dança como mascotes]. A gente até botou apelido nos fithos do pessoal da matutos de matutinos. Todos eles dançam, a gente faz um figurinozinho padrão, todos dançam. Neste ano de 2012 dançou o meu, o do Aleanderson. Entrou o da Maria, a da Zizi também. É assim, quando vai aparecendo menino [designação genérica para criança], é matutino. (Jimi, entrevista concedida ao autor em janeiro de 2013)

Com 12 anos, a filha de Cleyber, ${ }^{9}$ então marcador e um dos coordenadores da Matutos na Roça, fazia sua estreia "na linha", ou seja, dançava oficialmente no grupo, mas não se comportava como uma iniciante. Cleiciane demonstrava muita segurança na realização das coreografias, e dificilmente "pegava banco" nos ensaios ou apresentações. Pegar banco é, como em um jogo de futebol, dar lugar a outros dançarinos, ficar na reserva. Esse marcador me revelaria que a família materna dessa filha era envolvida com grupos juninos há duas gerações, mesmo antes do período de emergência dos festivais e concursos.

Os pais influenciam muito. O envolvimento do pai sempre vai chegar no neto ou bisneto. Minha filha acompanhou muito quadrilha quando morava com a mãe dela. Ela sempre teve curiosidade, sempre gostou. A mãe dela também foi brincante de quadrilha. Isso já tava no sangue dela (...). Ela já vem de uma influência maior, antes de mim. A família da mãe dela já vinha no movimento, e eu cheguei depois. Isso já faz com que a criança goste, se envolva. Tenha a curiosidade de participar. Traz a responsabilidade pra eles também de manter essa tradição. Hoje se você analisar - você participou e viu - setenta por cento daqueles brincantes de média idade, juventude, foi por influência familiar, um primo, um vizinho, e de alguém que já passou por ali. Isso influencia muito tanto na família, quanto na comunidade. E a participação das crianças na apresentação é uma coisa espontânea. Eles estão ali, os pais constroem um figurino pra eles, educa eles: "vocês tem que só se manter num posicionamento que não atrapalhe”. Eles não tem uma finalidade fixa. Eles se divertem na dança, na brincadeira, mas não participam do conjunto que está completo. Uma hora ou outra ele vai querer tomar um espaço, querer entrar pra dançar. (Cleyber, entrevista concedida ao autor em janeiro de 2013)

Uma brincante de outra quadrilha junina relatou, com orgulho, que no festival estadual de 2013 seu filho de 6 anos, que se apresentava na condição de mascote, "pareou" com o noivo da quadrilha durante a dança e reproduziu a performance com primor. Percebemos que a interação desde a infância no cotidiano do grupo, a experimentação livre e a imersão na "brincadeira"propicia às crianças um laboratório privilegiado para a construção de um aprendizado consistente das habilidades de dança e de inserção na dinâmica do grupo. Mais do que isso, a inserção na convivência com o grupo aparece como a porta de entrada para um papel "social" do grupo na comunidade.

[O envolvimento das crianças] é uma forma de incentivar para estar dentro do grupo, para incentivar que futuramente, quando estiver crescendo, com sua formação, ele não caia no mundo errado, que não mexa com alcoolismo, com drogas. A gente procura incentivar os meninos que dançam quadrilha a estudar. Nós temos hoje formados dentista, enfermeira, camelô, meu caso, sou autônomo, e outros tipos de vida. (Jimi, entrevista concedida ao autor em janeiro de 2013)

Os grupos quadrilheiros aparecem, no relato do marcador abaixo, como articulados às comunidades. Muitos jovens passam pelos grupos e, por diferentes circunstâncias da vida, deixam de dançar. Muitos mantêm vínculos, maiores ou menores, com os grupos de suas comunidades, seja apoiando-os em atividades de preparação, seja incentivando seus filhos e familiares jovens a participar, ou até mesmo a fazer parte da torcida nos festivais.

Hoje as pessoas saem das comunidades para acompanhar suas quadrilhas, eles vão pra torcer, como uma torcida de futebol, que fica gritando o nome do time. Quando pensa que não, tão lá as famílias, simpatizantes, pessoas que acompanharam os ensaios. Isso muda muito a rotina de uma comunidade quando tem essa transformação geral. Quando ela é coletiva. Porque tem alguns grupos que se mantêm ainda na ideia do trabalho só para disputar o campeonato, sem envolver a comunidade. O processo domovimento junino não é o mesmo do atleta de futebol, que é negociação. Hoje eu estou aqui, amanhã os estudos ou o trabalho não me deixam mais participar. Não porque eu queira, mas por necessidade. E outras coisas mais na vida da gente que vão mudando. Isso é que tira a gente da quadrilha, não do movimento. As pessoas continuam, mesmo sem poder ensaiar, com seus familiares mais novos, com seus jovens, dando aquela força, aquele incentivo na participação. Os grupos que trabalham com a comunidade têm essa vantagem. Por isso que se mantém com um número expressivo de cerca de sessenta, setenta pessoas no grupo, porque trabalham com a comunidade. Um grande exemplo disso é a Pega-pega. É uma quadrilha que todo ano muda de brincante por estudo, por isso, por aquilo, e entram outros novatos. Porque eles têm um trabalho de comunidade. (Cleyber, entrevista concedida ao autor em janeiro de 2013. (Grifos adicionados) 
Acompanhei de perto o engajamento de ex-brincantes da Matutos na preparação do grupo. Bem próximo do festival, uma experiente brincante que se encontrava afastada passou a frequentar os ensaios, desempenhando um importante papel no treinamento da coreografia. Ela e seu companheiro, que também já dançara no grupo, abriram sua casa para a confecção dos figurinos. Desta forma, as quadrilhas que possuem essa penetração nas comunidades dos bairros, sobretudo com a existência de uma rede de ex-membros e simpatizantes, acabam desempenhando um "papel social" em seu meio.

O retorno de tudo isso sempre vai ser aquele trabalho social que a quadrilha tem hoje. Hoje nosso grupo já tem essa ideia de que as pessoas têm de estudar, ter uma relação familiar boa, uma boa educação, uma boa imagem, têm de ter alguma coisa que possa fazer com que as pessoas que vejam ele como quadrilheiro tenham respeito, não o ver como um qualquer. Se fizer uma análise no grupo, hoje 60\% estuda, 30\% trabalha, 5\% é aquele chove não molha, e os outros $5 \%$ não conseguiram ainda se habituar no mundo, estudar, trabalhar. Isso influenciou muito na comunidade, os pais vendo essa situação, familiares, vizinhos, vendo essa mudança radical da própria personalidade da pessoa, conseguem se envolver e compreender que está havendo alguma coisa nova. E isso oferece uma segurança maior pra eles, porque assim os filhos deles não estão indo para a marginalidade, drogas, não tão se envolvendo com outros tipos de situações que possam futuramente trazer problemas sociais. (Cleyber, entrevista concedida ao autor em janeiro de 2013)

Percebe-se, portanto, uma série de mecanismos de transmissão das técnicas e do modo de ser e de agir do quadrilheiro, no processo de tornar-se parte daquele grupo, de uma comunidade, de uma "família", como alguns grupos se autodenominam. Algo muito próximo do tratamento dado por Lave e Wenger (1991, p. 29) à aprendizagem como "atividade situada":

Learning viewed as situated activity has as its central defining characteristic a process that we call legitimate peripheral participation. By this we mean to draw attention to the point that learners inevitably participate in communities of practitioners and that the mastery of knowledge and skill requires newcomers to move to- ward full participation in the sociocultural practices of a community. (Grifos adicionados) ${ }^{10}$

\section{A pedagogia do marcador}

Ao acompanhar o cotidiano de um grupo quadrilheiro, foi possível perceber, em seu processo de ensino e aprendizagem da prática do dançar, um papel semelhante ao que Wacquant (2002) atribui ao treinador de boxe, ou seja, afigura do marcador. Este é responsável por guiar a transição entre os passos, mas também desempenha uma função pedagógica evidente, pois é ele quem intervém quando os erros se sucedem, interrompendo o ensaio e propondo um momento de marcação de passos, sem música, evidenciando a memorização. Alguns ensaios podem ser realizados totalmente nesse formato, e são os chamados "ensaios técnicos".

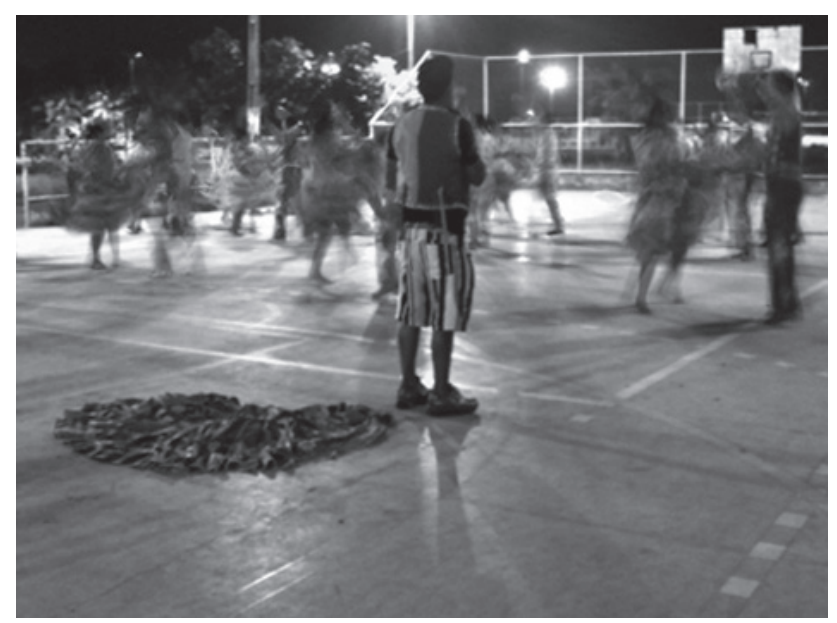

Figura 2 - O marcador/gritador da Matutos na Roça, conduzindo um ensaio técnico na quadra de esportes do bairro Aeroporto Velho.

Fonte: Foto de Eduardo Di Deus (junho 2012)

O marcador, junto com brincantes experientes, coordena também a "escolinha", um momento dedicado exclusivamente aos novatos sem experiência prévia em quadrilhas, uma espécie de intensivo que pode ocorrer antes do início dos ensaios. ${ }^{11}$ É ele também, em geral, que propõe as novas coreografias a

\footnotetext{
10. Tradução livre do trecho citado: "Aprendizagem, vista como atividade situada, tem como sua característica central definidora um processo que nós chamamos de participação periférica legítima. Com isso queremos chamar a atenção para o ponto em que os aprendizes inevitavelmente participam em comunidades de praticantes e que o domínio de conhecimentos e habilidades requer dos novatos que busquem uma participação plena nas práticas socioculturais de uma comunidade".

11. Outro aspecto do processo de aprendizagem mereceria maior atenção: o desenvolvimento da habilidade com figurinos e adereços, como saias, para as damas, e chapéus, para os cavalheiros. A destreza no balanço das longas e pesadas saias das damas é fundamental no tipo de dança que se realiza. Testemunhei "escolinhas" para novatas, com a finalidade específica de aprofundamento nesse quesito. Para os cavalheiros, o domínio do momento e a maneira correta de tirar e colocar o chapéu, e principalmente não deixar que caiam, podem significar o ganho ou a perda de pontos em concursos.
} 
cada ano e coordena o processo coletivo de definição das alterações e adaptações necessárias. Também interage com os brincantes nos ensaios, apontando a necessidade de balanceamento entre os movimentos e as expressões, "entre a técnica e o sentimento", segundo relatou-me o marcador/gritador da Matutos. Ele explicou certa vez que há diferentes estilos dessa atuação, diferentes perfis que a pessoa responsável por coordenar a transição dos passos pode ter:

Na minha visão tem marcador, animador, gritador e narrador, são quatro tipos. Se a gente for buscar pela ideologia da palavra, a gente vai entender cada um. Marcador, o que faz? Ele marca, ele tem uma percepção do tempo, da coreografia, disso e daquilo, mas ele não se identifica no espetáculo da dança. O gritador é aquele cara que entra no espetáculo, quando se trata de gritar: "vamos lá! Isso, aquilo!". Essa é outra das características do gritador. O animador é aquele que levanta o público, que dança junto, que demonstra como se faz, e faz junto. Ele é o conjunto de tudo. E o narrador é aquele que só narra, que diz a coreografia e ponto. Dentro do que eu tenho percebido durante os últimos anos há uma diferença destas personalidades. [...] Marcador, gritador, animador e narrador são as pessoas que usam o microfone para fazer a quadrilha caminhar, só que as maneiras são diferentes, os estilos são diferentes, é o que percebo. E me enquadro na ideia mais do gritador. Sou aquele que não sabe dançar muito, mas estou lá no meio, fazendo meu barulhinho e seguindo a quadrilha. Não entro muito na coreografia, faço a marcação junto com o grupo na hora do espetáculo, mas estou lá, gritando e fazendo meu comercial, participando. (Cleyber, em entrevista concedida ao autor em janeiro de 2013)

Para além dessa pedagogia do dançar, a figura do marcador/gritador e dos demais coordenadores é revestida de um papel de liderança no grupo e na comunidade, um papel social, conforme já mencionado, que se formou a partir de uma mudança na visão que antigamente se tinha sobre as quadrilhas, vista como espaços de marginalidade.

Quem entra neste movimento junino para coordenar ele aprende a ser psicólogo, advogado, doutor e tudo. Porque de tudo ele tem que saber um pouco. Nessas horas a gente tem que ser pai, tem que educar, tem que brigar, tem que passar a mão. Tem que dar conselho, tem que conversar, tem que construir toda uma relação que você totalmente não se formou pra isso. Tem aqueles mais problemáticos, que você tem que dar uma de psicólogo. Com aqueles mais violentos você tem que dar uma de durão, mostrar pra ele que o mundo não é aquilo. Aqueles que tão mais perdidos no mundo você tem que incentivar, pra ele ter uma estabilidade social melhor, relação familiar. (Cleyber, em entrevista concedida ao autor em janeiro de 2013)
Antigamente o pessoal achava que quem dançava quadrilha era quem não tinha o que fazer, marginal. Hoje tem várias pessoas trabalhando, em profissões diferentes. Tem doutor, tem autônomo, tem comerciante, tem dentista. Eu faço a quadrilha, porque tenho horário para trabalhar, para entrar em casa, de fazer quadrilha, de brincar, de beber, de conversar, levar os filhos pra assistir cinema, tudo a gente faz na vida, tudo dá de conciliar, depende da gente [...] Ser coordenador de quadrilha é responsabilidade, muita responsabilidade. Ser coordenador é ser pai, irmão, um bom advogado, Assistente social, é ser doutor, é ser tudo. Por isso tem que ter mais de um, para dividir. (Jimy, em entrevista concedida ao autor em janeiro de 2013)

Percebe-se que o marcador e os coordenadores oferecem aos jovens condições de um múltiplo aprendizado. Propiciam-lhes as condições para aperfeiçoarem-se nas técnicas da dança da representação do casamento caipira; inserem-nos em uma dinâmica competitiva com grupos de outros bairros da cidade; iniciam alguns deles nas relações políticas existentes, como a participação na Liga de Quadrilhas e suas interações com o poder público municipal e estadual. Sobretudo, são as referências que fazem a mediação da entrada desses jovens em uma identidade de suas comunidades, como parte de um movimento jovem e ativo de grande relevância para a sua conformação como sujeitos.

\section{Algumas questões de gênero}

Um último comentário que gostaríamos de fazer diz respeito a uma questão de gênero. Significativo número de quadrilheiros identifica-se ou é identificada como gay, categoria que aparece localmente como uma designação mais geral para diferentes experiências de gênero que exteriormente poderiam ser nomeadas homoafetivas, bissexuais e transgêneros. Esses grupos configuram ambientes de socialidade que incluem pessoas discriminadas na sociedade mais ampla por suas experiências de gênero. Em um determinado momento do trabalho de campo, percebi que um brincante, heterossexual, demonstrou conhecimento de uma linguagem cifrada, de origem em línguas africanas, o Pajubá, utilizada comumente por travestis.

Para além de uma convivência respeitosa, um fenômeno chama a atenção: em alguns grupos é facultada a possibilidade de alguns gays - em geral aqueles que na vida cotidiana possuem experiência transgênero - dançarem no papel de damas. Com base no que vimos discutindo a respeito das quadrilhas como um movimento em que corpo e pessoa se articulam na construção dos sujeitos, encontramos em Moore (2007) elementos para iniciar uma consideração desses fenômenos. Essa autora propõe uma abordagem para 
pensar "como nos tornamos seres sexuados", 12 dialogando com dois outros autores citados anteriormente, Ingold e Lave (Moore, 2007, p. 9-10). Com Ingold, Moore busca elementos para repensar a maneira pela qual se processa o crescimento, o desenvolvimento das pessoas, em críticas do que chama a "tese da socialização", pensando a articulação entre aprendizado orgânico e social, e considerando o engajamento do sujeito no mundo como parte de seu desenvolvimento. Com Lave, Moore (2007) reforça a ideia de que "knowing, thinking and understanding are generated in practice" (p. 10). Assim, traz um peso importante para a prática no processo de tornar-se um ser sexuado. Vemos queos grupos quadrilheiros são espaços de performatividade de gênero, no sentido atribuído por Butler (2003), que questiona a existência de construtos de identidade de gênero fechados, de sexualidades específicas. Entendo a performatividade de gays dançando como damas, ou dançando como cavalheiros, como processos em que as identidades de gênero estão em constante re-criação, em uma manifestação respeitosa a essa diversidade de gênero. E não somente nos movimentos quadrilheiros isto ocorre. Há uma constante circulação de brincantes quadrilheiros para outro forte movimento da cidade, de bandas marciais, ou fanfarras. É comum que gays assumam posições nas coreografias desses grupos.

\section{Referências}

ALMEIDA, Mauro W. B. Rubber tappers of the upper Jurua River, Brazil: the Making of a Forest Peasantry. Tese (Doutorado em Antropologia Social) - University of Cambridge, Cambridge, 1993.

ALVIM, Valeska R.; LOBO, Andréa M. F.; ENCARNAÇÃO, Flávio L. Um olhar sobre a quadrilha no Acre: transfiguração de uma festa. COLÓQUIO INTERNACIONAL DE ETNOCENOLOGIA: A VOZ DO CORPO, O CORPO DA VOZ: ARTES E CIÊNCIAS DO ESPETÁCULO. Anais... Belo Horizonte: Ed. UFMG, 2009. p. 391-396.

BUTLER, Judith. Problemas de gênero: feminismo e subversão da identidade. Rio de Janeiro: Civilização Brasileira, [1990] 2003.

CARDIA, Lais Maretti. Cumprindo trajetos, refletindo sobre a memória: colonos e seringueiros migrantes em Rio Branco, Acre - uma abordagem antropológica. Rio Branco: EdUFAC, 2010.

CHIANCA, Luciana de Oliveira. Quando o campo está na cidade: migração, identidade e festa. Revista Sociedade e Cultura, v. 10, n. 1, p. 45-49, jan./jun. 2007.

COSTA, Arleilson S. da. O Anarriê na cidade de Rio Branco:

\section{Considerações finais}

Fazer parte de um grupo de quadrilha junina é uma das maneiras pelas quais jovens moradores dos bairros da cidade de Rio Branco iniciam um tipo de participação em redes de socialidade. A experiência vivenciada em um grupo específico e no movimento junino no ano de 2012 possibilitou as observações que fizemos acima sobre a relação entre o aprendizado da técnica e a construção da pessoa. Ser quadrilheiro, assim como pertencer a outros movimentos urbanos, é uma forma de inserção dos jovens de grande parte dos bairros populares da cidade em redes de relações, que se mantêm mesmo com a constante renovação dos brincantes ativos. Como vimos, muitos dos que deixam de participar do cotidiano dos ensaios como brincantes passam a ser apoiadores em diversos níveis: atuação política, preparação de figurinos e cenários, auxílio em ensaios específicos de coreografias, elaboração de enredos e temas para casamento caipira, incentivo a brincantes jovens, ou mesmo mediante a participação nos festivais e concursos, fortalecendo a torcida. A renovação dos quadros de brincantes ocorre nos processos práticos de imersão de crianças e jovens na vida dos grupos. Nesses processos não são repassadas tradições uniformatadas, e sim condições para a continuidade desses engajamentos em redes de relações.

tradição e inovação nas quadrilhas juninas. Monografia (Graduação em História). Universidade Federal do Acre, Rio Branco, 2011.

DI DEUS, Eduardo. Antropologia e ambiente: entre transgressões e sínteses. Dissertação (Mestrado em Antropologia Social) - Departamento do Antropologia, Universidade de Brasília, Brasília, 2007.

DUARTE, Luiz Fernando Dias. Da vida nervosa das classes trabalhadoras urbanas. Rio de Janeiro: Jorge Zahar/ Brasília: CNPq, 1986.

INGOLD, Tim. The perception of environment: essays on livelihood, dwelling and skill. London: Routledge, 2000. KLEIN, Daniel da S. A conquista de Rio Branco: movimentos comunitários e direitos humanos na capital acreana de 1970 a 2000. Belém: Paka-Tatu, 2009.

Em homenagem a São João: os tempos das festas juninas em Rio Branco, Acre (1920-2010). (Mimeo.).

LAVE, Jean; WENGER, Etienne. Situated Learning: Legitimate Peripheral Participation. Cambridge: Cambridge University Press, 1991.

LUCENA, Giselle; BARROS, José Márcio. Diversidade cultural e conselhos de cultura: uma aproximação concei- 
tual e empírica. In: RUBIM, A. A. C.; FERNANDES, T.; RUBIM, I. Políticas culturais, democracia e conselhos de cultura. Salvador: EdUFBA, 2011. Disponível em: <http://observatoriodadiversidade.org.br/site/pesquisa/pesquisas/>.

MAUSS, Marcel. Sociologia e antropologia. São Paulo: Cosac \& Naif, [1950]2003.

MENEZES NETO, Hugo. O Balancê no arraial da capital: quadrilha e tradição no São João do Recife. Dissertação (Mestrado em Antropologia) - Universidade Federal de Pernambuco, Recife, 2008.

MOORE, Henrietta. The subject of anthropology: gender, symbolism and psychoanalysis. Cambridge and Malden: Polity Press, 2007.

MORAIS, Maria de Jesus. Crescimento urbano de Rio Branco, Acre, Brasil. 8 Encuentro de Geografos de America Latina, Santiago. Cd 8 Encuentro de geográfos de America Latina. Santiago: Universidad de Chile, 2001.

PESSOA, Jadir de Morais. Saberes em festa: gestos de ensinar e aprender na cultura popular. Goiânia: Kelps/Ed. UCG, 2005.

RANZI, Cleusa Maria Damo. Raízes do Acre. Rio Branco:
EdUFAC, 2008.

SAUTCHUK, Carlos Emanuel. O arpão e o anzol: técnica e pessoa no estuário do Amazonas (Vila Sucuriju, Amapá). Tese (Doutorado em Antropologia Social) - Universidade de Brasília, Brasília, 2007.

SAUTCHUK, João Miguel. A poética do improviso: prática e habilidade no repente nordestino. Brasília: Ed. UnB, 2012.

SILVA, Luiz Custódio da. Os festejos juninos e a reinvenção das identidades culturais no contexto paraibano. (Mimeo).

SILVA, Priscila S. Vida de quadrilheiro: notas etnográficas dos bastidores da quadrilha junina século XX, AracajuSE. SEMINÁRIO DE ESTUDOS CULTURAIS, IDENTIDADES E RELAÇÕES INTERÉTNICAS. Anais... Universidade Federal de Sergipe, agosto 2009. STRATHERN, Marilyn. O Gênero da Dádiva: problemas com as mulheres e problemas com a sociedade na Melanésia. Campinas: Ed. da Unicamp, [1988]2006.

WACQUANT, Loïc. Corpo e alma: notas etnográficas de um aprendiz de boxe. Rio de Janeiro: Relume Dumará, 2002.

\title{
Quadrilhas juninas as a youth movement in Rio Branco, Acre
}

\begin{abstract}
The current quadrilhas juninas put into motion a large number of people in their activities in the city of Rio Branco, Acre (Brazil), which are not restricted to the June events. They constitute one of the strongest cultural movements of this state, both in the context of dialogue with the public policies for culture, and in their communities of origin. There they occupy public spaces and provide an environment of sociability for the youth of these communities. This paper reflects on an anthropological research about the social construction of the personhood of quadrilhas juninas in the neighborhoods of Rio Branco and the process of learning the body techniques.
\end{abstract}

Key words: quadrilhas juninas, youth, construction of the personhood, body techniques, learning.

\section{Quadrilhas juninas como un movimiento de juventud en Rio Branco, Acre}

\section{Resumen}

Las quadrilhas juninas contemporáneas movilizan grandes cantidades de personas en sus actividades en la ciudad de Rio Branco, Acre, que no se limitan a las fechas de las fiestas de junio. Constituyen uno de los movimientos culturales más fuertes de este estado. Su fuerza se genera tanto en el contexto del diálogo con las políticas públicas de cultura, como en sus comunidades de origen, donde los grupos ocupan espacios públicos y ofrecen un ambiente de socialización a los jóvenes de estas comunidades. Presentamos reflexiones de una investigación antropológica sobre la construcción social de la persona de los brincantes de quadrilhas juninas en los barrios de Rio Branco y sus articulaciones con los procesos de aprendizaje de las técnicas del cuerpo.

Palabras clave: quadrilhas juninas, juventud, construcción de la persona, técnicas del cuerpo, aprendizaje.

Data de recebimento do artigo: 9/12/2013

Data de aprovação do artigo: 6/8/2014 